\begin{tabular}{lllllllllllllllllllllllllllllllll}
\hline$R$ & $E$ & $V$ & I & S & T & A & D & E & E & S & T & U & D & I & O & S & I & N & T & E & R & N & A & C & I & O & N & A & L & E & S
\end{tabular}

\title{
El creciente papel de China en los mercados de América del Norte
}

\author{
Víctor López Villafañe
}

Para los países integrantes del Tratado de Libre Comercio de América del Norte (TLCAN), la emergencia de China ha implicado un cambio en la forma en que se conduce la economía de la región y en la forma en que se relacionan entre sí. La presencia de China en Norteamérica es hoy una realidad ineludible y su fortaleza en el interior de dicho espacio geográfico crece a pasos agigantados, y hasta ahora, el país asiático es el que ha cosechado los mayores beneficios de esta situación. China ha sido así una especie de miembro no formal del área del TLCAN y lo más importante es que ello no le ha significado ningún costo, como a México o Canadá. China es actualmente el segundo socio comercial más importante tanto de Estados Unidos, como de México y Canadá. Así, las relaciones en el interior de la región se han modificado y las condiciones económicas y prioridades también. ¿Qué efecto ha tenido el crecimiento de la participación de China en la zona del TLCAN? ¿Cómo han reaccionado Estados Unidos, Canadá y México ante esta nueva fuerza? Especialmente en el caso mexicano, puede decirse: que ha habido un error en la interpretación y análisis de la participación y competitividad de China en Norteamérica; que China está enfrentando una gran fricción comercial con los Estados Unidos; que México requiere nuevas estrategias para poder competir con los productos chinos. México confronta a las industrias chinas principalmente dentro del mercado estadounidense, pero la amenaza real para el país es la merma de su poder manufacturero y el escaso crecimiento económico de su mercado nacional. Hoy como nunca antes, México y China enfrentan posibilidades de confrontación y cooperación. Sin embargo, ambos países se necesitan y a partir de este hecho es posible que se inicie una etapa más constructiva en el futuro. 


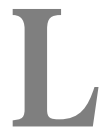

a fortaleza del crecimiento de China tomó por sorpresa al mundo. Sin embargo, lejos de ser una cuestión de suerte y de resultados inmediatos, solo se requiere voltear a ver la historia de ese país para comprender que siempre ha jugado un rol de gran importancia en términos económicos y políticos. Justamente, el despliegue del poderío chino que observamos hoy es el resultado de una planeación concreta y disciplinada iniciada a finales de la década de los años 1970 no exenta de problemas y desafíos.

Para los países integrantes del Tratado de Libre Comercio de América del Norte (TLCAN), la emergencia de China ha significado un cambio en la forma en que se conduce la economía de la región y en que dichos países se relacionan entre sí. La presencia de China en Norteamérica es hoy una realidad ineludible y su fortaleza al interior de dicho espacio geográfico crece a pasos agigantados, con la consecuencia de que, hasta ahora, los mayores beneficios de esta situación han sido precisamente para el país asiático. China ha sido así una especie de miembro no oficial del área del TLCAN y, lo más importante, su membresía no ha tenido ningún costo como para México o Canadá. China es hoy el segundo socio comercial más importante tanto de Estados Unidos, como de México y Canadá. Así, las relaciones en el interior de la región se han modificado y las condiciones económicas y prioridades también. ¿Qué efecto ha tenido el crecimiento de la participación de China en la zona del TLCAN? ¿Cómo han respondido Estados Unidos, Canadá y México a esta nueva fuerza?

\section{La emergencia de China ha modificado la forma en que se conduce la economía de la región.}

México, en particular, se ha visto doblemente afectado por la presencia china, debido a la continua rivalidad entre los productos mexicanos y chinos, tanto en el mercado nacional como en el estadounidense. Las cifras indican que comparado con China, México ha venido perdiendo competitividad en el territorio estadounidense, lo que se confirma si observamos que ya desde 2003 China reemplazó a México como segundo socio comercial de los Estados Unidos. Este factor es fundamental si se tiene presente que, para México, su principal socio comercial sigue siendo Estados Unidos -el receptor más importante de sus exportaciones (85\%).

Así, la disminución de la participación de México en el mercado estadounidense, la merma de la inversión extranjera directa, y la salida de capitales y empresas del país son todos eventos relacionados con el fenómeno chino, originados en tierra mexicana. Las pruebas del éxito chino son fáciles de observar: en 2004, el déficit comercial de México con China fue de 12 mil millones de dólares y en el 2005 se elevó a 15 mil millones. Este desequilibrio debería ser indicador suficiente para promover una revisión de la política aplicada a China. Al respecto, cabe preguntarse si en ese país hay algún aliciente para modificar las condiciones y términos de su relación con México. Ahora bien, para poder comprender las implicaciones de esta 
relación, es preciso tener presente la situación en que se encuentran Canadá y Estados Unidos respecto de China.

Las características de la China de hoy pueden enumerarse de la siguiente manera: es el país con mayor población en el mundo y el principal exportador de tecnología informática, el segundo en poder de compra, el tercero en inversión militar, el cuarto en superficie, la quinta potencia exportadora y desde 2005, la sexta economía del mundo, ya que el crecimiento del PIB fue de $9.8 \%$ y llegó a $\$ 1.85$ billones de dólares ${ }^{1}$. Precisamente, el PIB ha venido creciendo a un ritmo promedio de 9\% anual desde que se iniciaron las reformas económicas más importantes en 1978 (ver el cuadro 1 para su contraste con los países del TLCAN). En este escenario, el gigante asiático se ha propuesto doblar su PIB del año 2000 en 2010, proyección que, de acuerdo a Wen Jiabao -primer ministro chino-, es «activa y pru- dente». Su afirmación resulta viable si se tiene en cuenta que para lograrlo requiere crecer a razón de $7.5 \%$, al año, es decir, 2 puntos porcentuales menos que en 2005 . Además, China ha demostrado que es capaz de alcanzar estos objetivos: entre 1980 y 1997, cuadruplicó su PIB y su capacidad de ahorro aumentó en $280 \%$ entre 1978 y 1999. Por lo tanto, si logra su objetivo, en 2010 China habrá logrado incrementar su PIB per cápita de $\$ 1,600$ dólares a \$1,700 dólares.

En 2005, el fisco chino recaudó cerca de 3 billones de yuanes y su comercio bilateral rebasó los 1.38 billones de dólares. Además, China es el segundo país receptor de inversión extranjera en el mundo (tan solo detrás de los Estados Unidos), que en 2004 superó los 70 mil millones de dólares, y lejos de ser un país identificable únicamente por su mano de obra barata, presenta hoy innovación tecnológica, industrial y empresarial.

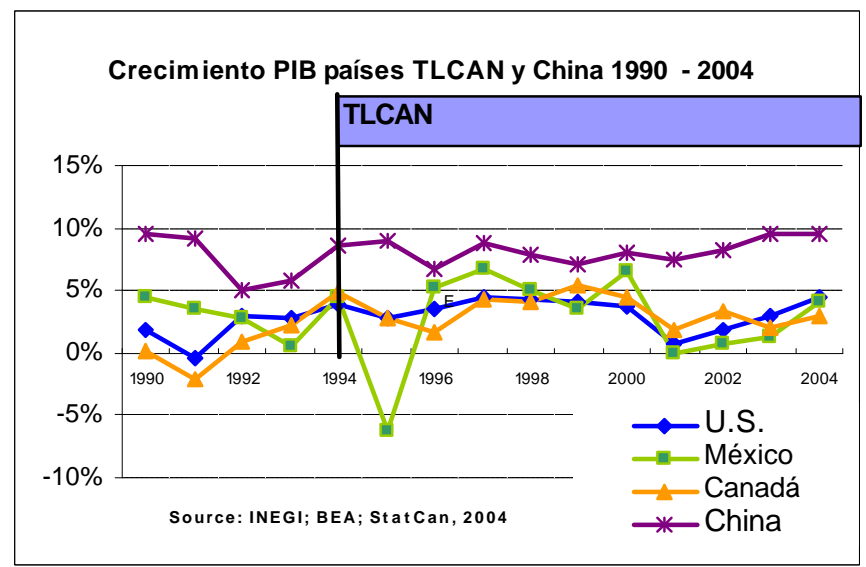

Cuadro 1

1 Hoy está en discusión si no debería considerársela la cuarta economía del mundo por su potencial de crecimiento y los rangos que ha manejado desde finales de los setenta. 
En cambio, desde su ingreso al TLCAN, México ha venido experimentando procesos irregulares en su crecimiento, demostrando así la inconsistencia del modelo que ha hecho que el crecimiento de sus exportaciones, que en el período de 1994-2000 se aproximó a 22,7\% -superando a China cuyo promedio fue $21,2 \%-$, se estancara e incluso se redujera a partir de 2001. Fue así como en 2003, como ya se dijo, China desplazó a México como segundo socio comercial de Estados Unidos y desde julio de 2005 se ubica como su principal exportador.

La relación de China y México con Estados Unidos es fundamental para comprender el efecto que tiene China en la región del TLCAN. Si observamos los índices de importación de Estados Unidos, encontramos que México ocupa la tercera posición, con un total de $\$ 155.843 \mathrm{mi}-$ llones de dólares en el año 2004, lo que supera en $12,9 \%$ la cifra registrada en 2003. Sin embargo, esto no ha sido suficiente, pues las ventas de China a ese mismo país se elevaron a $\$ 196.699$ millones de dólares y crecieron un $29 \%$ respecto de 2003 (ver el Cuadro 2). Esto im- plica que, si bien las cifras de México no son decrecientes, sino que por el contrario, incluso pueden ser alentadoras, son insuficientes para competir con China y, por lo tanto, pueden llegar a perder capitales, inversiones y empresas.

Esta situación se vuelve más preocupante cuando nos percatamos de que, pese a que México ya no es para Estados Unidos el socio estratégico de antes, no ha logrado aumentar el número de otros países a los cuales exportar y con los cuales comerciar. Esto es, México sigue siendo un país altamente dependiente de Estados Unidos, lo que se comprueba por el hecho de que ese país, el segundo importador más grande para Estados Unidos, superado únicamente por Canadá, mientras que China ocupa el quinto lugar al respecto. De tal manera que, mientras que China tiene una gama más amplia de países de los cuales abastecerse, México mantiene un enfoque especialmente centrado en su vecino del norte. Así, en 2004, las compras de México a los Estados Unidos, alcanzaron a $\$ 110.775$ millones de dólares, mientras que China solo compró \$34.721 millones de dólares (ver el Cua-

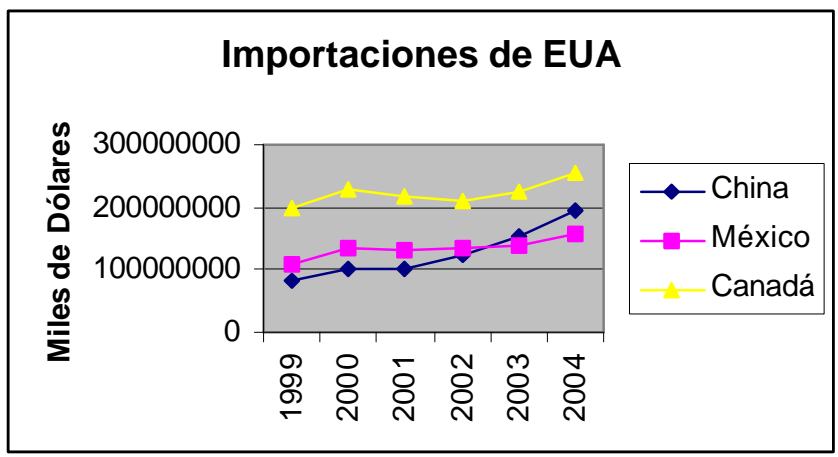

Cuadro 2 
dro 3). En consecuencia las importaciones de México desde los Estados Unidos crecieron 13,7\% en el bienio 2003-2004, lo que indica un incremento de la dependencia de dicho país, mientras que las compras de China han aumentado solo un $6,1 \%$.

Junto con esto, si se observa la balanza comercial entre ambos países, el crecimiento de las importaciones estadounidenses desde China se compensa ampliamente. En 2004 el comercio total entre China y Estados Unidos fue de \$245 mil millones de dólares, con un crecimiento de $28 \%$ respecto del año anterior, con lo cual el déficit de los Estados Unidos es el mayor del planeta, no solo actualmente sino de la historia, ya que en 2005 llegó a $\$ 160$ mil millones de dólares (ver el Cuadro 4). En cambio, en 2003 los otros miembros del TLCAN alcanzaron un superávit con Estados Unidos de $\$ 92.319$ millones, de los cuales $\$ 51.671$ millones correspondieron a Canadá y $\$ 40.648$ millones a México.

Tal como menciona Oropeza (2005), la ventaja de China al competir con México no radica tanto en los centavos de dólar de diferencia en los salarios, sino en la estrategia que hay detrás de cada producto.

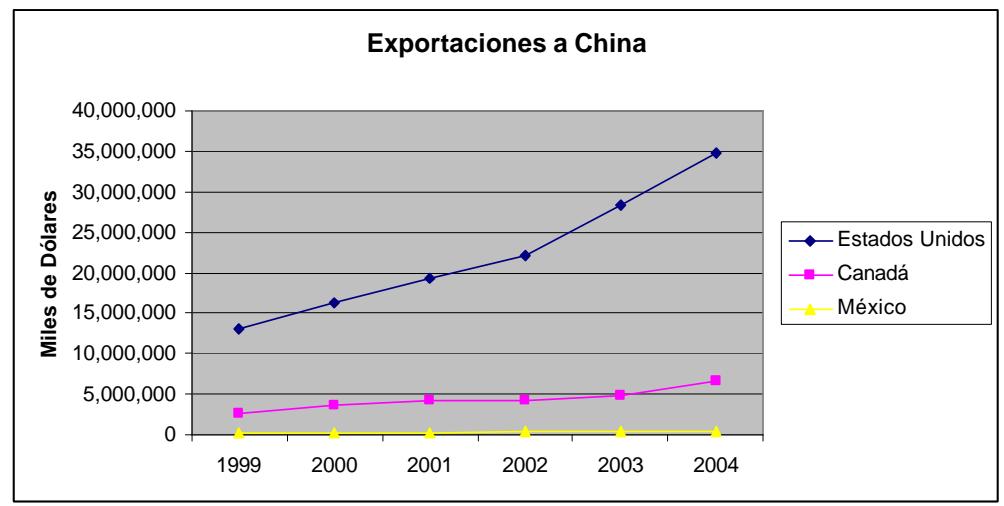

Cuadro 3

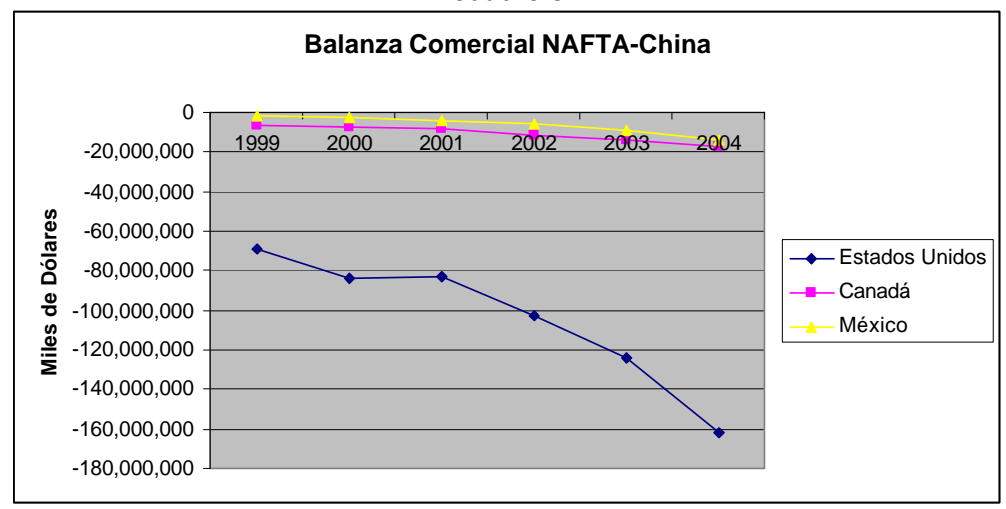

Cuadro 4 
Mientras que las mercancías chinas han sido trabajadas y apoyadas como proyecto de Estado, es decir, cuentan con todo un aparato de soporte, las mexicanas se desarrollan en forma privada. Esta es una realidad que explica el continuo éxito chino, pese a que México presenta mejores indicadores en ciertas áreas consideradas importantes para la competitividad, tales como mejor regulación, mayor protección de la propiedad intelectual, la productividad del trabajo calificado, el bajo costo del transporte a Estados Unidos y, sobre todo, el acceso preferencial derivado de la pertenencia al TLCAN.

Este último factor es de gran importancia: la apuesta que hizo México en los años noventa por un modelo de asociación y libre comercio con sus vecinos del norte ha surtido un efecto positivo en la medida en que le ha permitido crecer y mantener hasta hoy un superávit en la relación con Estados Unidos. Sin embargo, lo que se constata es que China no ha requerido de un tratado de libre comercio para entrar fuertemente a la economía estadounidense. Por otro lado, el TLCAN significó para México una serie de costos económicos y sociales, como por ejemplo, la pérdida de empleos en las zonas rurales, mientras que en China el aumento del comercio con Estados Unidos se hizo libre de cargas como las asumidas por México ${ }^{2}$.

Este hecho es aún más relevante si se observa que existe una competencia directa entre los productos chinos y los mexicanos en el interior del mencionado mercado (ver Cuadro 5). Si se comparan los principales ganadores y perdedores en materia de competitividad en Estados Unidos entre 1992 y 2004, encontramos que México ocupa el segundo lugar ganador con un total de $\$ 48,9$ mil millones de dólares, mientras que a China le corresponde el primer puesto con un total de $\$ 134$ mil millones de dólares. Ahora bien, si se examina a quiénes se les ha ganado ese espacio, tenemos que México obtuvo su parte (un total de $\$ 60,9$ mil millones de dólares) principalmente a expensas de Japón (28\%), Canadá (23\%) y Taiwán

\begin{tabular}{|l|r|r|l|r|r|}
\hline \multicolumn{5}{|c|}{ Ganadores y perdedores en competitividad en el mercado de Estados Unidos } \\
$(1992-2004, \$$ mil mdd) \\
\hline \multicolumn{1}{|c|}{ Ganadores } & \multicolumn{2}{c|}{ Ganancia } & \multicolumn{1}{c|}{ Perdedores } & \multicolumn{2}{c|}{ Pérdidas } \\
\hline China & 134.0 & $46 \%$ & Japón & -112.6 & $38 \%$ \\
\hline México & 48.9 & $17 \%$ & Taiwán & -36.0 & $12 \%$ \\
\hline Irlanda & 17.1 & $6 \%$ & Canadá & -27.5 & $9 \%$ \\
\hline Rusia & 9.4 & $3 \%$ & Gran Bretaña & -20.9 & $7 \%$ \\
\hline Otros & 83.4 & $28 \%$ & Otros & -95.8 & $33 \%$ \\
\hline Total & 292.9 & $100 \%$ & Total & -292.9 & $100 \%$ \\
\hline Fuente: Chami (2005).
\end{tabular}

Cuadro 5

2 De acuerdo con Audley en la introducción de NAFTA's Promise and Reality (2004), el sector agrícola mexicano, donde todavía trabaja casi un quinto de la población, ha perdido 1,3 millones de puestos de trabajo desde 1994. 
(7\%); y si nos centramos en ver con quién perdió competitividad, es decir, \$12 mil millones de dólares, encontramos que China representa el 70\% (Chami, 2005).

Más aun, en 2002, ya un $61 \%$ de las mercancías y productos mexicanos competían directamente en el mercado de Estados Unidos con los chinos (Romero y Molina, 2003: 1157). Al respecto, es importante mencionar que el $55 \%$ de las exportaciones de México a Estados Unidos han consistido en artículos electrónicos, automóviles y repuestos de automóviles, y en todos estos sectores compite directamente con China. El resto de los productos en que se compite son los equipos de telecomunicaciones; equipo científico y profesional; computadoras de oficina y personales; manufacturas metalúrgicas y textiles. En 2003 (ver Cuadro 6), México solo conservaba un lugar superior en telecomunicaciones, electrónica, equipo profesional y en la industria automotriz (Martínez y Castillo, 2004). Asimis- mo, a partir de 2003, China sobrepasó a México como el principal exportador de prendas de vestir a los Estados Unidos, con ventas, por un valor de $\$ 7,3$ mil millones de dólares, contra $\$ 6,9$ mil millones de dólares de México. En este sentido, el ritmo de crecimiento de estas mercancías chinas ha sido de $1000 \%$, mientras que en el caso de México se esperaba un crecimiento de $5,1 \%$ en $2005^{3}$. Otro sector importante, el de muebles, se ha visto igualmente afectado, pues mientras China ocupa hoy el primer lugar en el mundo como productor de muebles, México ha caído dos lugares desde 2003, y actualmente ocupa el undécimo puesto ${ }^{4}$. En la industria automotriz la adopción de medidas es cuestión de tiempo, pues basta ver la última clasificación mundial para observar que China es el segundo productor de automóviles en el mundo, superado únicamente por Alemania.

De acuerdo con informaciones proporcionadas por el Banco de México, en

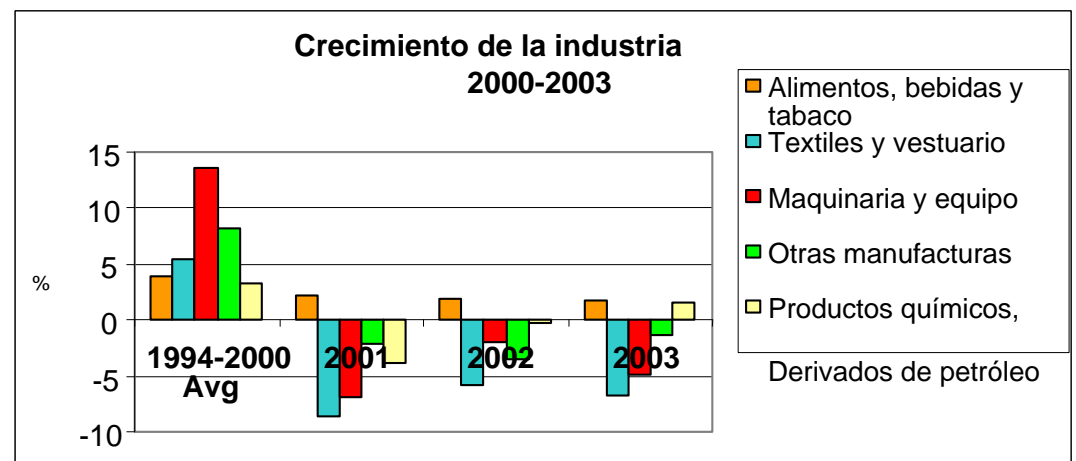

Fuente: López Villafañe (2005).

Cuadro 6

3 Si bien es cierto que las ventas de México en 2005 no crecieron en parte por el efecto de los huracanes, tanto en territorio estadounidense como mexicano experimentados en ese año (CNIV).

4 Dentro del mercado nacional, el $40 \%$ de los muebles son importados, principalmente de China. 
octubre de 2005 la caída de la competitividad con China en el mercado estadounidense en los últimos cinco años provocó a México una pérdida cercana a los $\$ 30$ mil millones de dólares. Esto implica al menos un punto porcentual del PIB por año y, en el caso de 2005, explica por qué el crecimiento del PIB no llegó a 5\% (Flores, 2005). Según Cornejo (2004), la creciente presencia china ha significado también la pérdida de por lo menos 730 maquiladoras y 229,127 empleos entre 2000 y 2003. Asimismo, de acuerdo con informaciones del Instituto Mexicano del Seguro Social (IMSS) entre octubre del 2000 y abril del 2005, la industria manufacturera ha perdido 824.000 empleos.

Estos indicadores revelan que es indispensable que México redefina sus objetivos y su política hacia China, pues de mantenerse la ecuación de este país con Estados Unidos al mismo ritmo de hasta ahora, no puede menos que aumentar el desplazamiento de la industria, el capital y los trabajadores mexicanos a un plazo no tan largo.

Ahora bien, no hay que engañarse, puesto que la relación de los Estados Unidos con China no es enteramente placentera para el primero. Si puede obtenerse un corolario de la relación económica entre ambos, basta mencionar que China es el segundo otorgante de créditos a Estados Unidos ${ }^{5}$, manteniéndose una deuda que en agosto de 2005 se elevaba a $\$ 248$ mil millones de dólares. Ese mismo año, las exportaciones de China a Estados Unidos superaron cinco veces las exportaciones estadounidenses (Mekay, 2005).

\section{Para Estados Unidos, su relación con China no es enteramente placentera.}

Por lo tanto, si bien se reconoce que la participación china en el mercado estadounidense le ha traído beneficios, como se dijo, el déficit comercial ha alcanzado niveles sin precedentes y Estados Unidos cada vez más comienza a percibir a China como una potencial amenaza, no solo en lo económico sino incluso en el terreno militar. Esto se comprueba en la declaración hecha por Roger W. Robinson Jr., vicepresidente de la U.S. -China Economic and Security Review Commission (USCC)-: «El impacto de China en la economía de nuestra nación [...] afecta de manera ineludible nuestra seguridad nacional» (en Mekay, 2005).

Las críticas que hacen tanto la USCC como la propia embajada de Estados Unidos en China se relacionan con el control que aún se ejerce sobre el renminbi (yuan), afirmándose que es injusto para la competencia entre productos. Por otro lado, se piden mayores facilidades para el ingreso de capitales estadounidense en China, especialmente en términos porcentuales, es decir, la posibilidad de ser dueños de un mayor porcentaje de los negocios emprendidos en China; y, finalmente, la protección de la propiedad intelectual. Adicionalmente, analistas como Bezlova (2005), Mekay (2005) y Solomon (2005) incorporan como preocupaciones de Estados Unidos el incremento de su déficit con China; así como la manifiesta com-

El primero es Japón. 
petencia de ambos países por las existencias internacionales de recursos naturales energéticos, pues actualmente China representa el $40 \%$ de la demanda mundial de estos. Finalmente, en materia de seguridad, a Estados Unidos le inquieta la creciente cercanía con países hostiles como Irán, Sudán, Corea del Norte, y ahora en América Latina, países como Venezuela.

El dilema hoy para Estados Unidos, tal como menciona Solomon (2005), es cómo mantenerse amistoso con su socio que crece a un ritmo más acelerado y que es una de sus principales fuentes de capital, y al mismo tiempo resguardarse de una potencial amenaza militar de un rival estratégico. Es decir, actualmente China y Estados Unidos son recíprocamente mejores socios potenciales y al mismo tiempo representan la mayor amenaza política.

Hasta ahora, la estrategia seguida por Estados Unidos se identifica con el llamado congagement, es decir, una mezcla de contención (containment) y compromiso (engagement). Esta estrategia tendría como característica el acercamiento y el continuo intercambio económico, al tiempo que la generación de nuevas alianzas militares con países cercanos a China. Evidencia de esta postura es el acuerdo anunciado por Rumsfeld según el cual se podrá instalar un carrier de aviones y baterías de misiles antibalísticos Patriot en Japón, el trato con India para compartir tecnologías nucleares de tipo espacial y civil, el acercamiento especial para el entrenamiento de tropas y mejoras militares, el entrenamiento militar conjunto con Vietnam, especialmente en programas de medicina y lingüística, y, finalmente, a Indonesia se le ha permitido participar en un programa de entrenamiento de tropas después de su exclusión en los años noventa (Solomon, 2005).

\section{La estrategia estadounidense es una mezcla de contención y compromiso.}

En lo que toca a la relación económica, nos encontramos, sin embargo, en un punto de quiebre, pues parece que Estados Unidos ha decidido ser un poco más agresivo respecto de la participación de China en su mercado. El caso más conocido al respecto fue el rechazo a que la compañía petrolera china CNOCC Ltd. adquiriese Unocal Corp. de manos estadounidenses, tras aceptarse en el Congreso la recomendación de la USCC de que resultaría peligroso aceptar la compra. Asimismo, desde hace unos meses han aumentado las propuestas de gravar las mercancías chinas únicamente basándose en su origen, esto es, que todo producto chino que entre en territorio estadounidense estaría afecto a un impuesto. Otra propuesta ha sido la de congelar los activos de las empresas chinas involucradas en la producción de armas o misiles.

Otro hecho que confirma este giro es el cambio en la percepción de China por el ciudadano estadounidense. Según el embajador de Estados Unidos en Beijing, Rob Portman, si hoy tuviera que votarse el acceso de China a la Organización Mundial de Comercio, el resultado sería radicalmente distinto al que mostraban las encuestas en 2001. En gran parte, esta postura deriva de una sensación de inequi- 
dad en el trato que se da a la mercancía estadounidense en China, respecto de la china en Estados Unidos.

\section{Actualmente México tiene mayor disposición a colaborar con el gigante asiático.}

Al tener presentes estos factores se comprende que China también debe evaluar la forma en que conduce su política y su economía en la región norteamericana. Y es que para China el reto también es grande, pues su actual superávit comercial con los Estados Unidos representa la cuarta parte del total, lo que implica que le resulta fundamental mantener su acceso y participación en el mercado estadounidense. Por lo tanto, si se siguen los consejos de organismos como la USCC, en el sentido de cerrar el acceso e imponer barreras arancelarias, China podrá perder buena parte de sus utilidades por concepto de exportaciones.

Parece ser que, justamente, China ha comenzado una estrategia de cambio y de inmersión distinta y que podría resultar favorable para México. Si revisamos los acontecimientos de los últimos tiempos, es posible constatar un esfuerzo por parte de China de acercarse a México. En 2003, Hu Jintao, presidente de China, declaró por primera vez a México socio estratégico y en 2005 le concedió finalmente el grado de destino turístico. Asimismo, en estos últimos dos años se han firmado tratados en ámbitos tan amplios como el comercio de productos agrícolas, la cooperación del sector minero, la doble tributación, el desarro- llo social, y la lucha contra la piratería china en México. Por otra parte, se ha buscado un mayor intercambio cultural, lo que se ha traducido en que China declarara 2006 el año de México, que implica la realización de numerosos eventos destinados a promover el arte, la cultura y la historia mexicanos. El reconocimiento incluye ser invitado de honor en el festival Encuentro Beijing, que tendrá lugar en mayo, y en el Festival Internacional de Cine de Shanghai, que incluirá una semana dedicada al cine mexicano.

¿Por qué esta manifestación de interés chino en México? Si sopesamos las condiciones que tiene México para acceder al mercado estadounidense, la prioridad china de seguir su participación en él y el aumento del sentimiento de amenaza en Estados Unidos, se comprueba que China tiene la alternativa para seguir expandiéndose. Un caso similar ocurrió antes con Japón en los años setenta y ochenta, cuando su participación en el mercado estadounidense era de tal magnitud que comenzó a generar alarma. La solución adoptada por los japoneses fue la de disfrazar sus exportaciones invirtiendo en varios países de América Latina y Canadá, de manera de que disminuyeran los focos rojos. Si China trata de disminuir las fricciones que tiene actualmente con Estados Unidos sin perder espacio real en su mercado, esta estrategia parece ser una solución viable.

La oportunidad que este hecho representa para México es enorme. Se trata de poder redefinir la relación mantenida hasta ahora con China y dejar de percibir a este país como amenaza y principal ene- 
migo para generar alianzas estratégicas y una sociedad especial que permita el desarrollo y el crecimiento de ambos. Parece ser que dicho mensaje ha sido entendido y que actualmente hay mayor disposición a colaborar con el gigante asiático, que ha sido bien recibida y se refleja en la propuesta de apertura de un consulado en Guangzhou, en la declaración del inicio de exportación de repuestos de automóviles a China (García, 2006) o en la reciente decisión de grupos empresariales mexicanos importantes, como Gruma, de comenzar a participar en el mercado chino.

México tiene hoy la oportunidad de alterar el equilibrio y la condición de su relación con China. El éxito de la estrategia lo muestra Canadá, que desde hace tiempo ha enfocado gran parte de su esfuerzo a generar una relación especial y privilegiada, en general con Asia Pacífico, y en particular con China. Si bien Canadá también ha perdido en su relación con Estados Unidos, en gran medida gracias a la participación de China y ha sufrido el incremento de los precios de las materias primas y energéticas por la creciente demanda china, el razonamiento que acompaña a su actitud va de la mano con el hecho de que el mercado chino y las posibilidades que ofrece son mucho más valiosas. Ya el gobierno de Paul Martin reconocía en su declaración de política internacional del año 2004 que China se convertirá en la economía más importante del siglo XXI y que se encuentra en el corazón de las cadenas de abastecimiento regionales y globales que afectan a Canadá. En ese mismo documento se manifiesta la intención de duplicar la intensidad de las relaciones con Asia Pacífico en 2010 (Departamento de Asuntos Exteriores de Canadá, 2004).

\section{Canadá tiene la mayor diáspora china del mundo.}

La relación entre ambos países ha llegado, por ejemplo, a la compra de una petrolera de origen canadiense en Kazajstán (PetroKazakhstan Inc.), por la petrolera china China National Petroleum Corporation (CNPC), o bien, a la participación y colaboración en aspectos tales como los derechos humanos: en noviembre de 2005 , Pierre Pettigrew, Primer Ministro canadiense, anunció la creación de un proyecto de atención a los derechos humanos de los migrantes en China por un total de 4,8 millones de dólares. Asimismo, Canadá ha aprovechado el hecho de que tiene la mayor diáspora china del mundo para crear negocios, fomentar los intercambios educativos y promoverse como vínculo entre Asia Pacífico y América del Norte.

Es posible constatar que las relaciones de China con cada uno de los países de Norteamérica presentan características distintas e inclusive puede afirmarse que ellas son asimétricas. El momento que se vive actualmente, dado que la política exterior de Bush se ha centrado en la seguridad nacional y la prioridad que tiene el mercado estadounidense para China, así como la capacidad creciente de este último permiten que se participe en una situación de cambio en la cual tanto Canadá como México pueden lograr acuerdos 
interesantes y posicionarse como socios vitales para China.

\section{Las economías de la ASEAN debieron reestructurarse debido} a la crisis asiática.

Finalmente, es importante resaltar cuatro conclusiones que se refieren especialmente al caso mexicano:

1. Ha habido un error en la interpretación y el análisis respecto de la participación y de la competitividad de China en Norteamérica. Si bien se la ha considerado como un fenómeno novedoso o una amenaza reciente para las industrias mexicanas, estadounidenses y canadienses, su presencia se ha dejado sentir desde al menos la entrada en vigor del TLCAN. Parte de la crisis asiática se debió al desplazamiento por las exportaciones chinas de las provenientes de algunos países de la ASEAN más Japón, Corea del Sur y Taiwán, llevando a una reestructuración industrial de dichas economías. Actualmente China se está convirtiendo en mercado clave para estas economías, compensando así las pérdidas originadas principalmente en el mercado estadounidense. En cambio México, debido a la enorme concentración de su comercio en los Estados Unidos no cuenta por lo pronto con otros mercados para compensar sus pérdidas frente a la competencia de los productos chinos.

2. China está enfrentando una gran fricción comercial con los Estados Unidos, derivada de su gran déficit, por lo que es probable que se vea forzada a adoptar una nueva serie de estrategias para poder minimizar la reacción estadounidense. Dicha estrategia puede llegar a consistir en seguir el patrón japonés adoptado en los años ochenta como respuesta al llamado Japan bashing (período de crítica aguda a Japón en los Estados Unidos), que podría traducirse en un mayor compromiso con el resto de las economías norteamericanas al establecerse redes productivas para conducir negocios directamente dentro del área del TLCAN. Siguiendo esta lógica, México y Canadá podrían convertirse en lugares importantes para nuevas inversiones chinas.

3. México requiere nuevas estrategias para poder competir con los productos chinos. Asimismo, debe desarrollar mayores y mejores capacidades tecnológicas, así como estrategias para sectores y regiones específicos dentro de los Estados Unidos.

4. México está enfrentando a las industrias chinas principalmente dentro del mercado estadounidense, pero su amenaza real es la disminución de su capacidad manufacturera y el reducido crecimiento económico de su mercado nacional.

Finalmente, cabe decir que este texto ha procurado poner énfasis en el estado de las relaciones entre México y China, y hoy, como nunca antes en el pasado, aparecen al mismo tiempo las posibilidades de confrontación y cooperación. Por diferentes razones, ambos países se necesitan y, a partir de este hecho, es posible que se inicie una etapa más constructiva en el futuro. 


\section{BIBLIOGRAFÍA}

«Ambassador Rob Portman delivers remarks on China-U.S. Relations» (2005), Transcripción, noviembre 14.

«Buscan empresas mexicanas conquistar a chinos por el estómago» (2005), en El Financiero. Ciudad de México, noviembre 18.

«Canada announces funding for Human Rights Project in China» (2005), en Asia Pacific Foundation of Canada, noviembre 4. Disponible en: 〈http://www.apfc.ca〉.

«China eyes strong growth to 2010» (2005), en Reuter, octubre 25. Disponible en: <http:// www.reuters.com>.

«CNPC completes acquisition of PetroKazakhstan» (2005), en China View, octubre 27. Disponible en: <http://www.chinaview.com.cn>.

«Estiman baja de 3,0 por ciento en exportaciones de textiles y vestido. Las ventas en el mercado nacional crecerán 5,0\% este año: CNIV» (2005), en El Financiero, Ciudad de México, Noviembre 18.

«Premier: GDP to exceed US\$1.85 trillion in 2005» (2005), en China Daily, octubre 20. Disponible en: <http://chinadaily.com.cn>.

Canada's International Policy Statement, Department of Foreign Affairs, Gobierno de Canadá, Disponible en: <http://www.dfaitmaeci.gc.ca>.

Industry, trade and economy: Data and Análisis, U.S. Foreign Trade Highlights (2005), julio 25. Disponible en: <http://www.ita.doc.gov/td/ industry/otea>.

Audley, John J. (2004), NAFTA's Promise and Reality. Lessons from Mexico for the Hemisphere, Carnegie Endowment for International Peace.
Bezlova, Antoaneta, «Politics: Bush visit to focus on China's rising economic power» (2005), en Global Information Network, Nueva York, noviembre 16.

Chami Batista, Jorge (2005), Competing for the U.S. Import Market: NAFTA and Non-NAFTA Countrie, Free Trade in the Americas Conference, octubre 6.

Flores, Leonor (2005), «Costó a México 30 mil mdd la pérdida de competitividad: Ortiz», en Milenio, Mexico, octubre 5.

García, Myriam (2005), «Da automotriz más inversión», en Reforma, Ciudad de México, enero 12.

López Villafañe, Víctor (2005), The Dragon in Aztec Lands, Robarts Centre for Canadian Studies, Disponible en: 〈http://www.robarts.yorku.ca〉. Martínez Cortés, José Ignacio y Castillo, Omar N. (2004), «La ventaja comparativa de China y México en el mercado estadounidense», en $\mathrm{Co}$ mercio Exterior, México: junio, Vol. 54, № 6 .

Mekay, Emad (2005), «China Comission Sounds Call for Punitive Action», en Global Information Network, Nueva York, noviembre 11.

Oropeza, Arturo, «México-China: La invasión del gigante amarillo», en Reforma. Ciudad de México, noviembre 13, 2005

Perrett, Bradley (2006), «Update: China economy grew 9.8 pct in 2005 - vice minister», en Reuters, enero 1. Disponible en: 〈http://www.reuters.com>.

Romero Hicks, José Luis y Molina Medina, Humberto (2003), «La transformación económica de China y sus implicaciones para México», en Comercio Exterior, México: diciembre, Vol. 53, No 12, pp. 1155 - 1165.

Solomon, Jay (2005), «U.S. Increasingly Pursues Two-Track China Policy; Economic, Security Goals Yield Approach Combining Engagement, Containment», en Wall Street Journal. Nueva York, noviembre 17. 